\title{
Determining Issues of the Economic Essence and Methodology of Foresight
}

\author{
Lamara Qoqiauri ${ }^{1} \bowtie$ \\ Nino Qoqiauri ${ }^{2}$ \\ 'Doctor of Economics Sciences, Academician of Georgian Economics Academy, Senior Research Scientist- \\ Coworker at the National Institute of Economic (AAEP), United Kingdom \\ Email:Lqoqiauri@yahoo.com Tel:599906011 \\ ${ }^{2}$ Master of Solkhumi State University, Georgia \\ Email:nino-qoqiauri@mail.ru Tel:577770616
}

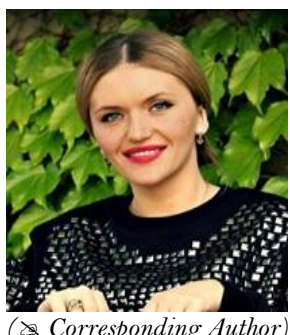

\begin{abstract}
The article discusses key issues of the origin, development and essence of modern foresight. There is explained three main program of foresight. In scientific -technical programming is the foresight a new event or not, how is it possible to positioning the foresight in strategic planning, is its methodology used at regional level or not, in the paper there are also given the stages of formation of foresight, the parallelization is given between forecast and foresight and it is justified that the participants of foresight create real possibilities not only for forecast, also they discuss the future possible alternatives and develop strategies to implement more promising projects. Methodological issues of foresight are also studied, in particular, normative and exploratory approaches, a wide range of methods used for foresight: Creativity, Expertise and Forecast, Analysis, Interaction -Delphi - Methods of Survey establishment on quality information.
\end{abstract}

Keywords: Determinants, Foresight, Delphi method, Strategic management, Explanatory approach.

Citation | Lamara Qoqiauri; Nino Qoqiauri (2018). Determining Issues of the Economic Essence and Methodology of Foresight. Economy, 5(1): 1-7.

History:

Received: 24 October 2017

Revised: 22 December 2017

Accepted: 3 September 2018

Published: 10 January 2018

Licensed: This work is licensed under a Creative Commons

Attribution 3.0 License (cc) E E

Publisher:Asian Online Journal Publishing Group
Contribution/Acknowledgement: Both authors contributed to the conception and design of the study.

Funding: This study received no specific financial support.

Competing Interests: The authors declare that they have no conflict of interests.

Transparency: The authors confirm that the manuscript is an honest, accurate, and transparent account of the study was reported; that no vital features of the study have been omitted; and that any discrepancies from the study as planned have been explained.
stures of the study have been omitted

Ethical: This study follows all ethical practices during writing.

\section{Contents}

1. Introduction

2. Review of Literature

3. Main Part

4. Conclusion

References..

Bibliography. 


\section{Introduction}

The world experience of the development of economics in the different fields of business truly proved that to develop economical business subjects effectively and in a stable way can be reached by total usage of innovations. In today's conditions different kinds of enterprises are functioning in quite difficult, indefinite, dynamically changeable space of social-economical environment. Innovations themselves support to reach favourable, strategic, competitive conditions in the market.

Nowadays the country's main goal of modern social-economic development is its movement towards innovative road, maximal usage of principally new factors of economical growth that is common for postindustrial informative era. This task is very important for modern Georgia. The necessity of movement to innovative road of the county's economics requires strong activization of innovative business. So to emphasize innovative sphere in the basis of development of its new directions will make it possible to overcome the problems of Georgia's big and traditionally increasing position of being behindhand ( in comparision with the world's highly developed countries in different field of economics.)

To manage effective innovative politics we consider the necessity of management of enterprises and innovations, new mechanisms of planning and prognosis formation, strategic projection of the county's dominant trends, to reveal factors of trends change.) Obviously, it is important to work out an acting plan on the basis of possible future development.

The above mentioned problems are not well studied in economical literature. In our article we aimed to study world experience of technological foresight research, its main point, aim and tasks. Besides we searched materials of foresight and principle features and stages of future prediction, combination of different methods of foresight, about the spheres of foresight usage.

\section{Review of Literature}

Composition of prognosis of development of the county's scientific technical sphere, to study technological foresight requires definite logical succession. We used Vienna and Brussels EC bureaucracy materials, as well as about scientific- technological foresight in economical literature. We also used European developed countries Austria, Belgium, Bulgaria, Finland, Germany, Italy, Spain, Great Britain’s etc, exiting materials abut foresight development organizations business.

During the work on the article we also based on papers of: (Barker and Smith, 1995; Saritas and Oner, 2004; Linstone, 2011; Kastro et al., 2012).

\section{Main Part}

The concept Foresight represents innovation for world, which is confirmed by the dynamics of distribution of this term and Foresight works. Herewith, this is one of rare cases, when innovation is first tested in the region and then - in the center.

The word 'foresight' foresees "looking into the future". In the most general form, foresight represents the system of forecasting. The most cited determination of foresight is that of American expert B. Martin, focused on the forecasted side of foresight, it focus on identification of strategically and socially important development zones. However, we consider this determination not to reflect all opportunities of foresight and its social-humanitarian sides (UNIDO Technology Foresight Manual. 2005) ${ }^{1}$.

Of course, single determination cannot cover all sides of foresight, as practical objective of the Article is theoretical development of the content of his term for the purpose of regional foresight, in this article we are interested in three main directions. First - does foresight represent new phenomenon compared to the scientifictechnical forecasting, taking place in our country; second - how can foresight be positioned in the field of strategic planning or, in wider sense, strategic management of the region; and third - foresight methodology is applied to the regional level.

Regarding the first issue, there are two opinions of the issue. One is that the foresight appeared in the 50s of last century in the company Rend Corporation², which developed Delphi method and applied it for the purpose of forecasting. This point of view, in fact identifying the term forecast and foresight, is represented in several foreign sources and sometimes is reproduced in the native publications.

Another method of approach exists in the fact that Foresight, as the system of forecasting was registered only at the end of $80 \mathrm{~s}$ of $20^{\text {th }}$ century. The matter is not the distinction in time, but in the principle of change. Foresight represents particular methodology, the essence of which is not only in forecasting of the future and in the agreed development of decisions regarding future in the field selected for foresight. It in fact solves the problems of achieving consensus in relation with the future through agreement of the interests of different social layers of public society, and in the active activity-related form. Thus, to our mind, it becomes not only prognosis, but also social and humanitarian technology. In such a holistic form as the socio-humanitarian technology of foresight was formed only at the end of the last century and this process is not yet completed.

The first foresights were carried out exceptionally for scientific-technical domain, due to which they were called the technological foresights. After this, from the field of defense, foresight tools was migrating social domain and policy to the economy and were being transformed into the market-oriented foresights. Social and cultural outcomes of occurrence and introduction of technologies (for example, influence of internet on the family, political institutes and organization of labor) were evaluated in them. Under modern conditions, foresight has been being concentrated to the discussion of different actual universally valid problems, such as the problem of hanger, poverty, security etc. When transferring to the third stage, foresight is becoming the technology for elite communication, forming consensus regarding view of the future in society.

${ }^{1}$ Technology forecasting first came to prominence in the late $1950 \mathrm{~s}$ in the United States deference sector and in work by consultants such an the RANZD Corporation. The latter were responsible for developing some of the principal fools of technology forecasting, such us the Delphi questionnaire survey and scenario analysis. Larger forecasting exercises ware carricd out during the $1960 \mathrm{~s}$ by the united states Navy and the united States air Force

${ }^{2}$ Delphi method - is considered one of the central method.
s.enario analysis. Larger forecasting exercises ware cariod 
Currently, foresight uses system instruments of influence in formation of the future, allowing foreseeing possible changes in all fields of social activities: science and technologies, economy, social, public relations, and culture. This is the reason for common use of "Foresight" without the adjective "Technological".

Frameworks for occurrence of foresight in world are observed by the specialists differently as well. For example, there is the opinion regarding the fact that there already were "full foresights" performed 10 years ago, and "the first complete foresight in Georgia was evaluation of the conditions and prospects of development of critical technologies, performed in 1997-1998", in which Delphi-surveys are applied. Next foresight in these series is "Scenario forecast of development of science and technologies before the year 2010". Essentially, the opinion that the forecasting works carried out in our country in 50 s represented foresights may be the option of this position.

Of course, occurrence of foresight in Russia may be classified only in case of identification and forecasting. To our mind, these processes are similar, but different and distinction between them may be demonstrated through analysis of the principles of foresight and forecasting (See the Table 1).

Let us review stipulated issues in details.

Let us review consistently - integral characteristic of Foresight, for which we refer to the history of different forecasts. As known, forecasting was originated long ago and, surprisingly, forecasts of scientists are much more exact, than those made by science fiction writers, giving rise to the idea of one-sidedness of scientific forecasts. Examples of unfulfilled technological forecasts are quite numerous; both in terms of denying the prospects of many of today's technical achievements that have entered our life, and, conversely, reassessing technical prospects. However, a number of technological forecasts can be considered erroneous only by implementation dates. Based on this, we can conclude that one-time technological forecasts should be systematically refined.

Table-1. Distinction of Forecasting and Foresight

\begin{tabular}{|c|c|c|}
\hline Parameter & Forecast & Foresight \\
\hline 1. Content & $\begin{array}{l}\text { The formulation of scientifically grounded } \\
\text { judgments about possible states in the future of } \\
\text { some object on the basis of current trends, } \\
\text { without taking into account the particular } \\
\text { interests of the players }\end{array}$ & $\begin{array}{l}\text { Developing a vision for the future, identifying } \\
\text { areas of research and the emergence of } \\
\text { technologies that can bring the greatest economic } \\
\text { and social benefits based on the desired future. }\end{array}$ \\
\hline $\begin{array}{l}\text { 2. Participants } \\
\text { and experts }\end{array}$ & Scientists, politicians & $\begin{array}{l}\text { Representatives of all key participants of } \\
\text { development: scientific-technical field, business, } \\
\text { government, society }\end{array}$ \\
\hline 3. Destination & Predicting options of the future & $\begin{array}{l}\text { Development of the image of the future; } \\
\text { concentration of resources on the directions } \\
\text { necessary for its achievement }\end{array}$ \\
\hline $\begin{array}{l}\text { 4. Method of } \\
\text { realization }\end{array}$ & $\begin{array}{l}\text { Enforcement of administrative orders or } \\
\text { convictions }\end{array}$ & $\begin{array}{l}\text { Encouraging the implementation of selected paths } \\
\text { based on the adoption of agreed upon interests } \\
\text { solutions }\end{array}$ \\
\hline $\begin{array}{l}5 . \quad \text { Influencing } \\
\text { processes }\end{array}$ & Recognizes existing trends & Shows possible ways of adjusting existing trends \\
\hline 6. Results & $\begin{array}{l}\text { Reports } \\
\text { Reports can be compared with the actual result }\end{array}$ & $\begin{array}{l}\text { Reports } \\
\text { Reports can be compared with the actual result }\end{array}$ \\
\hline
\end{tabular}

Source: Kovalev (2013).

Systematical forecasting of social and political processes is much more important, which has not been done within the framework of scientific-technical forecasting. Upon discussing the issue of distribution of Foresight, V. A. Nikonov stated that none of the real historic issues, overturning the fate of Russia and science was not forecasted; that preferences of scientific-technical policy often depend on political decisions; and the fact, how political management represent preferences from the point of politics, and not from the point of -technology.

It is interesting that within the framework of the foresight; in particular, in the development of foresight of the Company Shell, its futurists foresaw the collapse of the Soviet Union.

The history of development of Foresight, as the determined methodology demonstrates gradual shift from single forecasting to the systematic process of forecasting; from foreseeing opinions of the scientists to the foreseeing of the opinions of different layers and representatives of society; from forecasting technological processes to the prediction of social outcomes and the results of technical progress, and, in particular regard, to the forecasting of social processes.

Thus, if the prognosis is completed document ${ }^{3}$, which may be foreseen upon expiration of particular term, it may be possible to distract from such necessity, then the foresight represents permanent corrected process of forecasting, and developed as a result of foresight, the documents are reviewed depending on the changes, taking place in the society.

Following distinction touches upon participants. Forecasting is mainly performed by a corporation of scientists. Different layers of society participate in formation of the foresight as experts. Based on the international practice of development of foresights, not only the representatives of science, but also those of business field, public organizations and power structures, municipal formation, public movements, civil unions, and societies of scientists and experts perform the role of experts. Their opinion, their experience and interests are reflected in the discussions about possible state of the future. Besides this, establishment of the network of high-qualified and the participant concerned is important not less than the forecasting itself, in the result of foresight. These are the networks comprising of active citizens of different layers of society being able to form due response on the political, economic, social and other calls, as they, as participants of the process, have premonition to measures of precise preventive action and being ready to use the resources owned by them. 
Hence, forecast - this is the working of the grounded judgments about possible states of some objects in the future, based on the formed trend of its development. Foresight is comprised of the elements of active influence upon future, in the form of agreement of particular interests of different social layers of civil society, their aspirations and requests as direct participants of these processes. Foresight is more sensitive to these interests, being able to be concentrated on the cultural forecasting of changes in the society. When allocating zones of prospective investigations and denoting the emergence of key technologies, which may have the economic and social profit, foresight forms reference points for all active participants of public society.

If the forecast is greatly citing objective processes and shows the options and versions of the future, Foresight foresees opportunity for selecting the option of action depending of the "vision" of future, i.e. actually is directed towards designing of future and searching of the methods of its achievements; it also shows possible methods of their adjustment (Popper, 2007). Correspondingly, foresight stops being just a set of forecasting tools, i.e. obtains projection prospects for public changes.

Next purpose of Foresight is "sawing" opinion about different participants of social-economic life, in order to develop agreed opinions about future in the field, which is under Foresighting. Hence we may consider that foresight, according to its purpose, supports development of the experience of interaction and cooperation of state and scientists.

Important adverse product of the foresight is also named the mechanism of evaluation of technologies, project of programs, and political institute.

What is the position of Foresight in the system of strategic management of a region? It shall be noted that formulation of strategic management of a region itself is quite new. It is related with the theoretical assumptions regarding the fact that the region is an independent business entity. Despite significant theoretical progress in this direction, there also are the arguments regarding the fact that a region is not a business entity; it is only administrative-territorial formation within a country, carrying out federal regional policy. We used to ground the position regarding the fact that market economic system is based on the federal system of state structure, in which, market-safety grounds of which is competition of strategic economic units - regions. This is conditioned by the development of global competitive processed and those of global regionalization, where regions become subject not of only domestic, but also - international competition, and the regions of different levels of configuration.

In this regards, Foresight serves to develop a vision for the future of the region, taking into account national and global priorities, on the one hand, and resource, national-cultural, social and even mental peculiarities of the participants of regional economies.

It shall be noted that institutionally, forming of the system of strategic management of regions commenced long ago. State institute of regional management in person of the Ministry of Regional Development was established only in 2004. Currently methodological recommendations on development of the strategies of development of the subjects of federation have been developed. The strategies, in their turn, are considered and are subject to agreement with the working bodies of the Ministry. Agreement assignment includes determination of correspondence of strategies of development with of the subjects of the federation and sectorial strategies. At the same time, yet development of regional strategies do not represent mandatory mechanism. Moreover, institutional status of regional Foresight is not determined.

There is the issue of conformity of the strategy and Foresight. "Our" Foresight, to our mind, is comprised of the detailed development of the conducting of the fields, which are the most important for the region and selected for the regional foresight at the first stage of its conducting. Outcomes of Foresight make foundation for development of a strategy. On the other hand, Foresight may solve the issues of development of separate field in more details, which are not foreseen in the strategy. Besides this, Foresight solves the issues of widening circle of stakeholders, involved in the development of a strategy, improving methodology and technology of development of strategy, including a system of methods of its preparation, which are specific, characterizing for the Foresight (for example, forming experts' panels, conclusion of mental maps) and documents (for example, technological road maps, etc.).

Let us review methodological side of foresight. Foresight foresees particular methodology, allowing realization of its principles and achieving desired results, which does not represents completely lineal, strongly structured and formalized ones.

Methodology of Foresight is based on two methods of approach: normative and exploratory (search). Normative method of approach towards forecasting means orientation to the mission of subject (organization), requirements and objectives, achievement of which is the purpose of subjects. Normative method of approach begins from the determination of the options of desired future. It gives answer to the questions: which trends and events shall bring us to this future. Normative forecasting is confirmed by the movement in space of technologies from the technologies of higher level to the technologies of lower level, i.e. from requirements and purposes to the means of their realization.

Example of regulatory forecasting may serve to the forecasting in the field of space, when forecasted proved is represented in the form of continuous movement of technologies from the understanding of the problem of space to the field, which shall solve in favor of a human, up to the particular means of its solution - conditions for nuclear fission and amount of the energy released, etc.

Exploratory method of approach (in Russian literature it is also called surveying, researching or searching one) begins from the present and responds to the questions: which will happen in the future, in case of continuing essential trends.

Searching foresight is based on the orientation towards the further opportunities, determination of the trends of development of the situations on the basis, upon development of the forecasted information.

Example of searching foresight may be forecasting in the field of electronics, when forecasted process is represented in the form of the consistent technology transfer, starting from the quantum electrodynamics and completed with the instantaneous global communication.

The set of the methods used for foresight, is quite extended, they may be systematized through several criteria: per the type of foresight: normative (building desired future) or searching (formation of the image of the future based on the identified trends); per purposes (development of ideas or analyze), per tools (quantitative or 
qualitative), per methods of working with experts (full-time and part-time, surveys and direct personal interaction); per the degree of traditionalism and innovation.

Methodology instrument of foresight currently includes diverse methods of development of buildings in different sciences and applied fields, as traditional methods of forecasting, analyzing and development of ideas, so new creative methods developed in course of performing foresight works. Main methods, used today in course of conducting foresights, reflect its reasonable functions - forecasting (forecasting trends), analytical (analyzing existed situation), and creative (development of new ideas regarding the future). Particular methods, along with the stipulated functions, provide interaction of developers.

Correspondingly, entire set of the methods may be divided into 7 groups. In the materials of the United Nations Industrial Development Organization, all the methods are presented in the form of a diamond, on the angles of which there are characteristics of creativity (creative potential), expertise and forecasting, analyses and interaction are concentrated. Several methods may be used as for different purposes - for forecasting, learning environment and analyzing of trends, for development of the ideas regarding future and receiving ideas regarding current objectives of foresight (and correspondingly, they will be repeated in different groups).

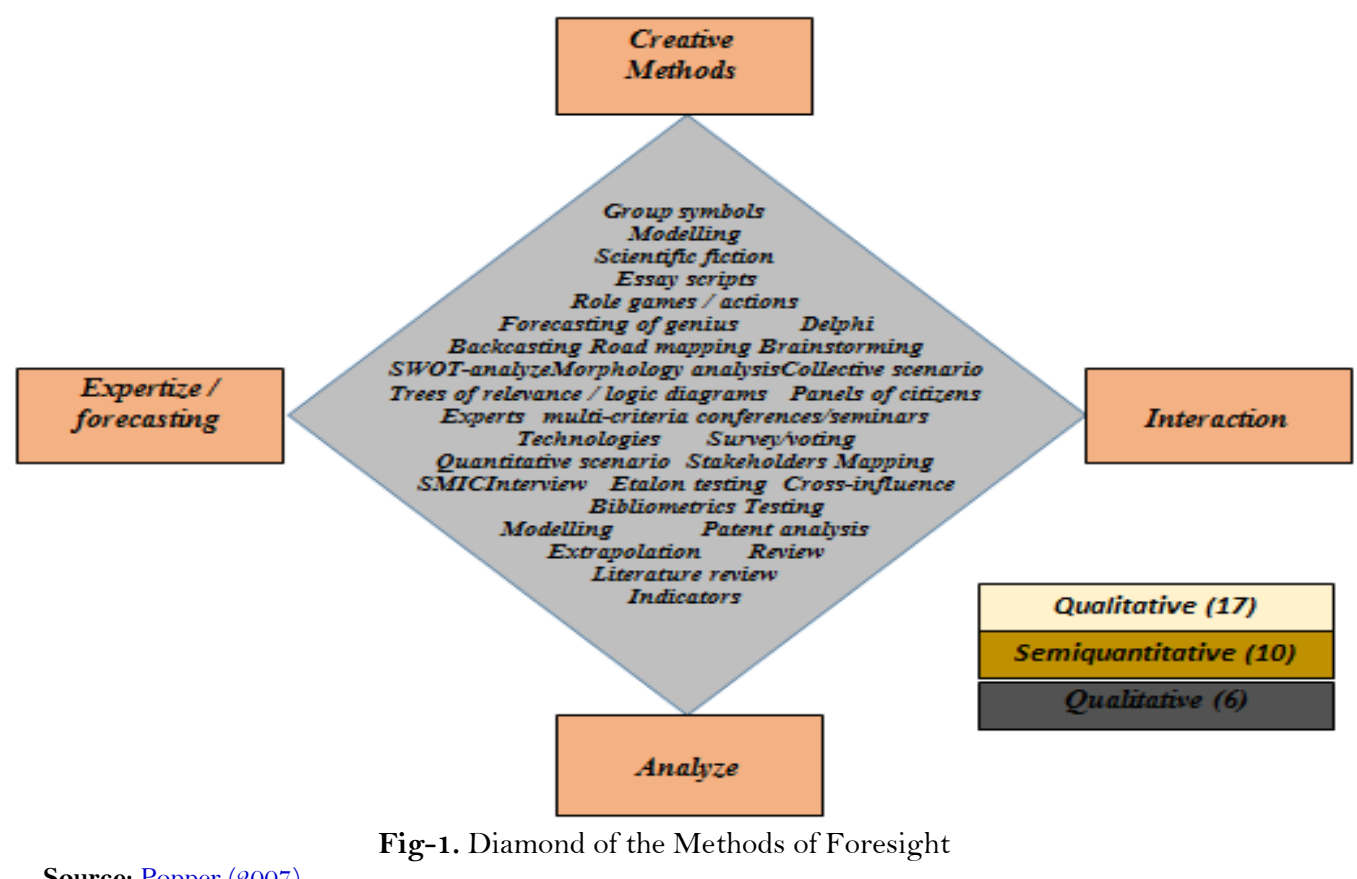

Correspondingly, we may count in this set 17 quantitative methods, 10 semi-quantitative and 6 qualitative Methods.

\section{Methods of Forecasting (Expertise):}

- Delphi Method,

- Scenario Development,

- Determination of Critical Technologies,

- Trend Extrapolation,

- Simulation Modelling,

- Critical/Key Technologies,

- Method of Historic Similarity,

- Other Methods Based on the Analyze of Exact Empiric Data.

Analyzing Methods:

- SWOT (Strengths, Weaknesses, Opportunities, Threats-Analysis),

- STEEPV,

- Cross-impact Analysis,

- Environmental Scanning,

- Expert Panels,

- Essay Preparation,

- Cross Impact Analysis,

- Relevance Trees,

- Balance score card.

Methods of Developing Ideas (Creative Methods):

- Experts' discussions,

- Focus-groups,

- Brainstorming,

- Conferences,

- Essay Preparation,

- Morphological Analysis. 


\section{New Creative Methods:}

- Wild cards,

- Technology Road Mapping, TRM,

- Relevance Trees.

Of course, some methods may serve as for the analysis, so - development of ideas.

Normative methodology is mostly uses Delphi-surveys and methods, basing on the qualitative information. Particularly, method of expert panels received extensive development, which were greatly oriented towards a work with not only quantitative, but also - qualitative information, received directly from experts. Qualitative information usually is represented in the form of verbal descriptions, when evaluations were obtained through verbal or verbally figurative scales, when there is information only about comparative assessments of alternative options. So-called "Success Scenario" and compiling "desired scenario of collective activities" are used, where participants are trying to establish a shared vision of the future, which represents as desirable, so - probable, and identification of the methods through which it might be achieved.

For searching Foresight other methods are more suitable, which are based on the analysis of the exact empiric data, in which preference is given to quantitative information. Using qualitative (non-quantitative) information in the searching Foresight is also possible. Example of this is the use of intuitive methods of the same method of scenario or the method of expert curves, allowing determination of the scheduled trends of changing situation, basing not only on the empiric data, but also on the experience of high-qualified specialist experts. The trends and influences are analyzed, investigations for determination of cross impacts are carried out, ordinary Delphi-method and some applications of the models.

Selection of the methods for particular program of Foresight, as a rule, is individual depending on the purposes and financial terms and conditions. Criteria for selection of the methods:

- Available resources (time, money, experience);

- Nature of desirable participation;

- Appropriateness for the combination with other methods;

- Desired methods for performance of foresight (for example, document or process);

- Quantitative/qualitative requirements of methods to the data;

- Methodology competence.

It is clear that methodology competence will become key factor in course of selection of methods. For example, at Baikal Forum in the report H. Funning they stated that they were carrying out Foresight of own Land (regions in Federal Republic of Germany are called Land), determining problems and desired vision under the method of Disney, which is not included into the Diamond of the methods of Foresight, and it may also be allocated to the creative methods. The definition of appropriate methods for the region requires special development.

\section{Conclusion}

So, the Foresight is system of expert assessment methods for strategic directions of social economic and innovative development, to find out technological breakthroughs that have the ability to influence the economy and in the medium and long term perspective.

Expert assessments are the bases for assessing future options. The Foresight's methodology has been selected to do a number of traditional and rather new products. At the same time, their constant perfection, methods and procedures are developed, which ensures the improvement of the perspectives of scientific-technical and socioeconomic development perspectives. The main sector of methodology development is aimed at more active and purposeful use of experts' knowledge of the project participants. Usually in every Foresight project, is used the combination of different methods, among these are the expert panels, the Delphi (expert survey in two stages). Swat analysis, mental storms, construction of scenarios, technological road maps, relevance trees mutual analysis and etc. In order to foresee possible options and get a full picture a large number of experts are invited. For example in the development of long-term forecasts of scientific-technical development in Japan, which is conducted in every five years, more than two thousand experts participate, they represent all important directions of science technology and techniques. And at the last Korean Foresight project more than then thousand experts participated.

Foresight is focused not just for alternatives, but also the choice of the advantageous ones. Selection criteria are used to select a comparatively advantageous option. For example criteria for achieving growth can be used when choosing critical technologies and for the field, when building road maps-identify potential market marks and Reveal and to choose those technologies which enable to work out competitive products for forming market as fast as possible. Choice of development strategy is carried out on the basis of order of wide expert consultations, that makes it possible to predict the most unexpected ways of development of events and possible "underwater cliffs".

Foresight thinks that desirable variant of future is greatly depended on sections that should be carried out today, so choice of variants are going on by working out those events, that will support optimal traecroty of innovative development.

Most Foresight projects, as a central component, includes perspectives of science and technological development. As a rule, these topics are subjects of judgement not only for scientists but also for politicians, businessmen, practician, specialists from different spheres of economics. The result of such discussions is formation of new ideas, which are connected to perfection of management mechanisms, to integration of science, education and economics and last, to increase of the state branch or the region competitiveness. Besides, the very " future prediction" - systematical efforts organization conditions formation of higher culture of management and finally, formation of more argumentative, scientific- technical and innovative politics.

Foresight- projects are oriented not only to get new knowledge as a form of speeches, set of scripts, recommendations, etc. its main result is development of informal interrelations among their participants and formation of the same opinion on the situation. 
In some projects horizontal branch areas are formed, in the frames of which scientists, businessmen, high school representatives and neighbouring sphere specialists systematically discuss common problems and it is understood as one of the main effects.

Foresight is formed as systemic process, which should be thoroughly arranged and organized. As a rule, foresight- projects are carried out quite regularly, sometimes by repeated scheme (as Japanese long-term prognosis, which has been carried out in every five years since 1971.) In other cases research is made as order of interrelated projects, that are aimed for solving interrelated tasks and about long - term perspectives on formation of agreed representation of Technologies, Innovations and Community development.

Foresight is more important approach than a complex compared to the traditional speech.

First of all, forecasts as a rule are established by a narrow circle of experts and in most cases it is associated with less predetermined events. (for example, forecast of Auction Course, Weather, Sports results). I the frames of foresight there is discussed the evaluation of possible perspectives of innovative development, which are related on science and technology forecasts, there are possible technological horizons, with can be achieved during the investing funds and during the systematic world. It is also probable effects for Economy and Society.

Secondly, Many experts are always involved in foresight (often through intensive interaction) from different fields of activity, which are related to the themes, of foresight projects and sometimes on the survey of a certain group of population (the inhabitants of the region, the youth...etc.), which are connected to solve problems.

Third, the difference between the foresight and forecast - is orientation on development of practical measures for approaching selected strategic orientation.

\section{References}

Barker, D. and J.H.D. Smith, 1995. Technology foresight using roadmaps. Long Range Planning, 28(2): 21 - 28. View at Google Scholar $\mid$ View at Publisher

Kastro, E.A., J.L. Marques and M. Borges, 2012. Foresight methodologies. Application to the housing market. Proceedings of the 52nd Congress of the European Regional Science Assotiation.

Kovalev, V.I., 2013. Foresight: Prognozirovanie innovatsii ili innovarsii v prognozakh? Vestnik Omskogo Gosudarstvennovo Universiteta, 2(68): $169-172$.

Linstone, H.A., 2011. Three eras of technology foresight. Technovation, 31(2-3): 69 - 76. View at Google Scholar | View at Publisher

Popper, R., 2007. Methodology: Common foresight practices and tools, in Georghiou, L., et al., International Handbook on Fore sight and Science Policy: Theory and Practice. Edward Elgar. Retrieved http:www.foresightnetwork.eu/files/reports/efmn_mapping_2007.pdf.

Saritas, O. and M.A. Oner, 2004. Systemic analysis of UK foresight results: Joint application of integrated management model and road mapping. Technological Forecasting and Social Change, $71(1-2): 27-65$. View at Google Scholar

\section{Bibliography}

Fischhoff, B., 1975. Hindsight is not equal to foresight: The effect of outcome knowledge on judgment under uncertaint. Journal of Experimental Psychology: Human Perception and Performance, 1(3): 288 - 299. View at Google Scholar | View at Publisher

Kaliujhnova, N. and S.I. Voilin, 2006. 20 questions and 20 answers. Irkutski. M: 12

Miles, I. and R. Popper, 2008. The handbook of technology foresight. Cheltenham: Edward Elgar. pp: 154.

Richardson, J., 2014. ICSU foresight analysis. International Science in 2013 - Exploratory Scenarios. Foresight, $16(2): 192$ - 195. View at Google Scholar

Roue, M. and D. Nakashima, 2002. Knowledge and foresight: The predictive capacity of traditional knowledge applied to environmental assessment. Roue M., Nakashima D., - UNESCO: 337 - 347. Retrieved http://www.botanischergarten.ch./Patents/RoueForesight-Int-Soc-Sci-1468-2451.00386.pdf.

Strategia, A. and C.A. Papadopoulou, 2013. Foresight analysis at the regional level - a participatory methodological framework. Journal of Management and Strategy, 4(2): 1. View at Google Scholar | View at Publisher 